\title{
Growth, Volatility and Political Instability: Non-Linear Time-Series Evidence for Argentina, 1896-2000*
}

\author{
Nauro F. Campos \\ Brunel University, \\ CEPR, IZA and WDI \\ E-mail:nauro.campos@brunel.ac.uk
}

\author{
Menelaos G. Karanasos** \\ Brunel University \\ (Corresponding author) \\ E-mail: menelaos.karanasos@brunel.ac.uk
}

September 2007

\begin{abstract}
What is the relationship between economic growth and its volatility? Does political instability affect growth directly or indirectly, through volatility? This paper tries to answer such questions using a power-ARCH framework with annual time series data for Argentina from 1896 to 2000 . We show that while assassinations and strikes (what we call "informal" political instability) have a direct negative effect on economic growth, "formal" political instability (constitutional and legislative changes) has an indirect (through volatility) negative impact. We also find preliminary support for the idea that while the effects of "formal" instability are stronger in the long-run, those of "informal" instability are stronger in the short-run.
\end{abstract}

JEL Codes: C14, O40, E23, D72

Keywords: economic growth, volatility, political instability, power-ARCH

* The authors thank Joseph Locke and George Stephenson for the encouragement, and seminar participants at the University of Macedonia and an anonymous referee for valuable comments on a previous version. The usual disclaimer applies.

** Address for correspondence: Menelaos G. Karanasos, Department of Economics and Finance, Brunel University, West London, UB8 3PH, U.K.; email: menelaos.karanasos@brunel.ac.uk; tel: +44 (0)1895265284, fax: +44 (0)1895269770. 


\section{Introduction}

What is the relationship between economic growth and its volatility? How does political instability affect growth? This paper tries to answer such questions using a power-ARCH (PARCH) framework and annual time series data for Argentina covering the period from 1896 to 2000 .

The paper tries to make three contributions. One is to bridge the literature on the macroeconomics of political instability (based on cross-sectional and short-panels evidence) with that on the relationship between growth and volatility (time-series based). ${ }^{1} \mathrm{~A}$ second is to try to shed light on two puzzles. One is on the sign of the relationship between volatility and growth: Ramey and Ramey (1995) show that output growth rates are adversely affected by their volatility, while Grier and Tullock (1989) find that higher standard deviations of growth are associated with higher mean rates. The second puzzle regards the duration of the political instability effects: while the conventional wisdom is that these are severe in the long-run, Campos and Nugent (2002) and Murdoch and Sandler (2004) argue that they are significantly stronger in the short- than in the long-run. The third intended contribution is to put forward novel econometric evidence on the Argentine puzzle: "Argentina's ratio to OECD income fell to 84 percent in 1950, 65 percent in 1973, and a mere 43 percent in 1987 (...) Argentina is therefore unique" (della Paolera and Taylor, 2003, p. 5, italics added). Argentina is the only country that was classified as developed in 1900, and as developing in 2000. Although a large literature associates this decline to political factors, ${ }^{2}$ we are unaware of studies that do it econometrically.

\footnotetext{
1 Durlauf et al. (2005) survey the former, and Grier et al. (2004) and Fountas and Karanasos (2007) review the latter. One paper that tries to link these literatures and is close to ours in this sense is Asteriou and Price (2001), which has time series evidence from UK quarterly data after 1960.

2 Acemoglu and Robinson observe that: "The political history of Argentina (...) reveals an extraordinary pattern where democracy was created in 1912, undermined in 1930, re-created in 1946, undermined in 1955, fully recreated in 1973, undermined in 1976, and finally reestablished in 1983" (2006, p. 7). See also della Paolera and Taylor (2003) and references therein.
} 


\section{Model}

The PARCH model was introduced by Ding et al. (1993) and gained currency fast in the finance literature. ${ }^{3}$ Let growth $\left(y_{t}\right)$ follow a white noise process augmented by a "risk premium" defined in terms of volatility

$$
y_{t}=c+k h_{t}+\lambda x_{i t}+\varepsilon_{t}
$$

with

$$
\varepsilon_{t} \equiv e_{t} h_{t}^{\frac{1}{2}}
$$

where $h_{t}$ denotes the conditional variance of growth, $x_{i t}$ is the political instability variable (where $i$ denotes assassinations, strikes, constitutional or legislative changes) and the symbol ' $\equiv$ ' indicates equality by definition. In addition, $\left\{e_{t}\right\}$ are independently and identically distributed (i.i.d) random variables with $E\left(e_{t}\right)=E\left(e_{t}^{2}-1\right)=0$, while $h_{t}$ is positive with probability one and is a measurable function of the sigma-algebra $\sum_{t-1}$, which is generated by $\left\{y_{t-1}, y_{t-2}, \ldots\right\}$.

Moreover, $h_{t}$ is specified as an asymmetric $\mathrm{PARCH}(1,1)$ process with lagged growth included in the variance equation

$$
h_{t}^{\frac{\delta}{2}}=\omega+\alpha h_{t-1}^{\frac{\delta}{2}} f\left(e_{t-1}\right)+\beta h_{t-1}^{\frac{\delta}{2}}+\gamma_{l} y_{t-l}+\phi x_{i t}
$$

with

$$
f\left(e_{t-1}\right) \equiv\left[\left|e_{t-1}\right|-\varsigma e_{t-1}\right]^{\delta}
$$

where $\delta$ (with $\delta>0$ ) is the "heteroscedasticity parameter," $a$ and $\beta$ are the $\mathrm{ARCH}$ and GARCH coefficients respectively, $s$ with $|s|<1$ is the "leverage" term and $\gamma_{l}$ is the "level"

\footnotetext{
${ }^{3}$ See, for example, Karanasos and Kim (2006). Karanasos and Schurer, (2005) use this process to model output growth in Italy.
} 
term for the $l$ th lag of growth. ${ }^{4}$ In order to distinguish the general PARCH model from a version in which $\delta$ is fixed we refer to the latter as $(\mathrm{P}) \mathrm{ARCH}$.

The PARCH model increases the flexibility of the conditional variance specification by allowing the data to determine the power of growth for which the predictable structure in the volatility pattern is the strongest. This feature in the volatility process has important implications for the relationship between political instability, growth and its volatility. There is no strong reason for assuming that the conditional variance is a linear function of lagged squared errors. The common use of a squared term in this role is most likely to be a reflection of the normality assumption traditionally invoked. However, if we accept that growth data are very likely to have a non-normal error distribution, then the superiority of a squared term is unwarranted and other power transformations may be more appropriate.

\section{Data}

Our data are from the Cross National Time Series Data set (Banks 2005) which contains historical series on income per capita and various dimensions of political instability. ${ }^{5}$ Data are available yearly for Argentina from 1896 until 2000, excluding the World War years. Income per capita is in constant U.S. dollars.

We use two measures of "formal" political instability: the number of legislative elections (defined as number of elections for the lower house each year) and the number of constitutional changes. The latter "reflects the number of basic alterations in a state's constitutional structure, the extreme case being the adoption of a new constitution that

\footnotetext{
${ }^{4}$ The model imposes a Box-Cox power transformation of the conditional standard deviation process and the asymmetric absolute residuals.

5 Banks is a commercial dataset that has been used extensively in the scholarship on growth and political instability (Durlauf et al. 2005).
} 
significantly alters the prerogatives of the various branches of government." These series are available since 1896.

We use two measures of "informal" political instability. Assassinations are defined as "any politically motivated murder or attempted murder of a high government official or politician," while general strikes are defined "as any strike of 1,000 or more industrial or service workers that involves more than one employer and that is aimed at national government policies or authority." The variable assassinations reaches its maximum in 1974 (16 assassinations registered) with second and third highest values (12 and 10) registered in the immediately subsequent years. Notice that general strikes does not cover sector-specific strikes. This peaks in 1969 (13 general strikes registered) with the second highest count registered in the subsequent year ( 7 strikes). These series are available since 1919.

The political instability measure with the largest average (standard deviations in parenthesis) is general strikes with 1.1 per year (0.2), followed by assassinations with 0.8 (0.3), legislative elections with $0.4(.05)$ and constitutional changes with $0.08(0.02)$.

\section{Results}

We proceed with the estimation of the $\operatorname{PARCH}(1,1)$ model in equations (1) and (2) in order to take into account the serial correlation observed in the levels and power transformations of our time series data. Tables 1 and 2 report the estimated parameters of interest for the period 1896-2000. These were obtained by quasi-maximum likelihood estimation (QMLE) as implemented in EVIEWS. The best fitting specification is chosen according to the Likelihood Ratio (LR) results and the minimum value of the Information Criteria (IC) (not reported). 
Once heteroscedasticity in the conditional mean has been accounted for, our specifications appear to capture the serial correlation in the growth series. ${ }^{6}$

In order to study the direct effects of political instability we specify model 1 with $\varphi=\mathrm{Yl}_{l}=0$, while model 2 (with $\lambda=0$ ) allow us to investigate their indirect effects. In most of the cases the estimates for the "in-mean" parameter $(k)$ are statistically significant and positive. The estimated ARCH and GARCH parameters $(\alpha$ and $\beta$ ) are highly significant in almost all cases. For model $1(\varphi=\mathrm{Y} l=0)$, when the "informal" political stability variables are used, the IC choose (P)ARCH model with power term parameter $\delta$ equal to 0.5 (the corresponding value for the "formal" political stability variables specification is 0.8 .) For model $2(\lambda=0)$, with the "formal" political instability variables Akaike IC (AIC) selects (P)ARCH models with $\delta$ equal to 1 , while when strikes are used the chosen value of $\delta(0.5)$ is lower than that for the specification with the assassinations $(0.8) .^{7}$

\begin{tabular}{|c|c|c|c|c|c|}
\hline & $k$ & $\lambda$ & $\alpha$ & $\beta$ & $\delta$ \\
\hline Assassinations & $\underset{(2.39)}{1.43}$ & $-\underset{(2.26)}{0.0012}$ & $\begin{array}{l}0.55 \\
(3.57)\end{array}$ & $\underset{(2.40)}{0.52}$ & 0.50 \\
\hline Strikes & $\underset{(2.75)}{0.84}$ & $-\underset{(2.27)}{0.0012}$ & $\begin{array}{l}0.56 \\
(4.26)\end{array}$ & $\underset{(3.43)}{0.53}$ & 0.50 \\
\hline Constitutional & $\frac{1.80}{(1.88)}$ & $-\underset{(1.35)}{0.0027}$ & $\begin{array}{l}0.56 \\
(2.01)\end{array}$ & $\underset{(1.35)}{0.48}$ & 0.80 \\
\hline Legislative & $\underset{(2.69)}{1.91}$ & $-\underset{(0.15)}{0.0003}$ & $\begin{array}{c}0.38 \\
(3.43))\end{array}$ & $\begin{array}{r}0.69 \\
(5.79)\end{array}$ & 0.80 \\
\hline
\end{tabular}

Table 1 reports parameter estimates for the following model:

$$
\begin{gathered}
y_{t}=c+k h_{t}+\lambda x_{i t}+\varepsilon_{t}, \\
h_{t}^{\frac{\delta}{2}}=\omega+\alpha h_{t-1}^{\frac{\delta}{2}}\left|e_{t-1}\right|^{\delta}+\beta h_{t-1}^{\frac{\delta}{2}} .
\end{gathered}
$$

The numbers in parentheses are absolute $t$ statistics.

\footnotetext{
${ }^{6}$ For all cases, we find the leverage term to be insignificant and therefore we re-estimate the model excluding this parameter.

${ }^{7}$ In the expressions for the conditional variances reported in Table 2, various lags of growth (from 1 to 12 ) were considered with the best model $(\mathrm{l}=6)$ chosen on the basis of the minimum value of the AIC. For all cases, there is strong evidence that growth affects its uncertainty positively. Hence, there is a positive bidirectional feedback between growth and its volatility (note the existing empirical literature focuses almost exclusively on the effect of volatility on growth, see Fountas and Karanasos 2007).
} 
From the results for Model 1 reported in Table 1, the parameters $\lambda$ for assassinations and strikes (our measures of "informal" political instability) reveal their direct, negative impact on economic growth, while the equivalent effects for our "formal" political instability variables (constitutional and legislative changes) are not statistically significant. It is worth noting that the former impact disappears after six years (results not reported). On the other hand, examining the results for Model 2 (reported in Table 2), and focusing our attention on the $\varphi$ parameters we can see that our "formal" political instability variables have indirect (through volatility) negative effects on growth, while these effects from assassinations and strikes are statistically insignificant. Interestingly, we find evidence that such indirect effect becomes stronger after three years (results not reported).

Table 2. In-mean-level (P)ARCH (Model 2: $\lambda=0$ ).

\begin{tabular}{|c|c|c|c|c|c|c|}
\hline & $k$ & $\alpha$ & $\beta$ & $\gamma_{6}$ & $\phi$ & $\delta$ \\
\hline Assassinations & $\begin{array}{l}1.09 \\
(2.72)\end{array}$ & $\begin{array}{l}0.68 \\
(5.30)\end{array}$ & $\begin{array}{l}0.27 \\
(5.84)\end{array}$ & $\underset{(5.84)}{0.27}$ & $-\underset{(1.45)}{0.0038}$ & $\underset{-}{0.80}$ \\
\hline Strikes & $\begin{array}{l}2.25 \\
(1.88)\end{array}$ & $\begin{array}{l}0.42 \\
(4.83)\end{array}$ & $\begin{array}{l}0.57 \\
(6.23)\end{array}$ & $\begin{array}{l}0.20 \\
(3.75)\end{array}$ & $\underset{(1.50)}{0.0035}$ & 0.50 \\
\hline Constitutional & $\begin{array}{l}1.18 \\
(1.94)\end{array}$ & $\begin{array}{l}0.69 \\
(4.40)\end{array}$ & $\begin{array}{l}0.45 \\
(4.15)\end{array}$ & $\begin{array}{l}0.18 \\
(3.75)\end{array}$ & -0.0077 & 1.00 \\
\hline Legislative & $\begin{array}{r}1.34 \\
(1.40) \\
\end{array}$ & $\begin{array}{l}0.45 \\
(2.79)\end{array}$ & $\begin{array}{l}0.57 \\
(5.45) \\
\end{array}$ & $\begin{array}{l}0.12 \\
(4.71)\end{array}$ & $\begin{array}{c}-0.0083 \\
(2.16)\end{array}$ & 1.00 \\
\hline
\end{tabular}

Table 2 reports parameter estimates for the following model:

$$
\begin{gathered}
y_{t}=c+k h_{t}+\varepsilon_{t} \\
h_{t}^{\frac{\delta}{2}}=\omega+\alpha h_{t-1}^{\frac{\delta}{2}}\left|e_{t-1}\right|^{\delta}+\beta h_{t-1}^{\frac{\delta}{2}}+\gamma_{6} y_{t-6}+\phi x_{i t} .
\end{gathered}
$$

The numbers in parentheses are absolute $t$ statistics.

\section{Conclusions}

Our main finding is that while "informal" political instability has a direct, negative effect on economic growth, "formal" political instability has mostly an indirect impact (through volatility). One main suggestion for future work is to investigate whether the effects of 
"formal" political instability are stronger in the long run while those of "informal" political instability are stronger in the short run (an idea for which we find preliminary support, as noted above).

\section{References}

Acemoglu, D. and J. Robinson, 2006. Economic Origins of Dictatorship and Democracy (Boston: Cambridge University Press).

Asteriou, D. and S. Price, 2001. "Political Instability and Economic Growth: UK Time Series Evidence," Scottish Journal of Political Economy 48, 383-399.

Banks, A., 2005. Cross-National Time-Series Data Archive. Jerusalem: Databanks International (http://www.databanks.sitehosting.net)

Campos, N. and J. Nugent, 2002. "Who is Afraid of Political Instability?" Journal of Development Economics 67, 157-172,

Ding, Z., Granger, C.W.J. and R. Engle, 1993. "A long memory property of stock market returns and a new model," Journal of Empirical Finance 1, 83-106.

Durlauf, S., Johnson, P. and J. Temple, 2005. "Growth Econometrics," in Philippe Aghion and Steven Durlauf (eds) Handbook of Economic Growth, North-Holland.

Fountas, S. and M. Karanasos, 2007. "Inflation, output growth, and nominal and real uncertainty: empirical evidence for the G7", Journal of International Money and Finance 26, 229-250.

Grier, K. and G. Tullock, 1989. "An Empirical Analysis of Cross-National Economic Growth, 1951-1980," Journal of Monetary Economics 24, 48-69.

Grier, K., Henry, Ó. T., Olekalns, N. and K. Shields, 2004. The asymmetric effects of uncertainty on inflation and output growth. Journal of Applied Econometrics 19, 551565.

Karanasos, M. and J. Kim, 2006. "A re-examination of the asymmetric power ARCH model", Journal of Empirical Finance 13, 113-128.

Karanasos, M. and S. Schurer, 2005. "Is the reduction in output growth related to the increase in its uncertainty? The case of Italy," WSEAS Transactions on Business and Economics 3, 116-122.

Murdoch, J. and T. Sandler, 2004, "Civil Wars and Economic Growth: Spatial Dispersion," American Journal of Political Science 48, 138-151. 
della Paolera, G. and A. Taylor, 2003. A New Economic History of Argentina, Cambridge University Press.

Ramey, G. and V. Ramey, 1995, "Cross-country Evidence on the Link between Volatility and Growth," American Economic Review 85, 1138-1151. 